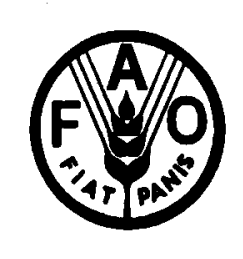

\title{
FOOD AND AGRICULTURE ORGANIZATION OF THE UNITED NATIONS
}

\section{Livestock Production for Food Security in Afghanistan}

\author{
Farmer Training Packages \\ Backyard Poultry Production
}

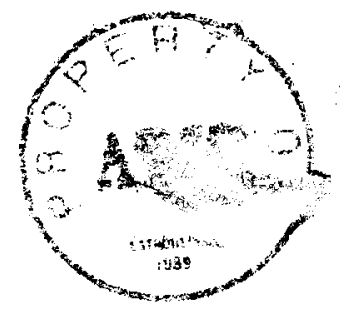

Package 10: Poultry Feeding

Package 11: Poultry Housing

Package 12: Poultry Diseases

Package 13: Poultry Breeding 


\section{Foreword}

The "Livestock Initiator Programme" (LIs) has been developed over time and has grown out of experience gained in the Afghan Integrated Livestock Programmes. A women's training component was originally included in the first cycle of the programme which started in July 1994 and the first women trainers were recruited in May 1995. The original concept was to train women basic veterinary workers (BVWs) and the training system was to have been developed by a UNV and an Afghan woman veterinarian. This approach was not altogether successful owing to the difficulties involved in the selection of suitable women to be trained.

In the meantime the PIHAM programme (Animal Health and Production Improvement Module) was started with Karen Iles (from the British research and consultancy group, Livestock In Development LID) as the trainer. Two additional Afghan women graduates were recruited and trained on that programme together with 10 male recruits. At the same time the original women's unit embarked on the training of village women in basic livestock production and back-yard poultry, which was also used as a method of evaluating and selecting, over time, potential BVW candidates. However at this time the PIHAM training gave a new perspective on how to reorientate the women's sector and their training needs.

Towards the end of the second year of PIHAM training (1997) Karen Iles took an interest in the women's programme and subsequently, in 1998, she joined the FAO programme in Islamabad for six months. She took on the training of the 12 women graduates who had been recruited as Livestock Initiators.

In October 1997 Karen trained the 12 women recruits in participatory methods, behaviour and attitudes and in needs assessment systems with regard to livestock activities. In 1998, in addition to participatory and technical training, she developed a comprehensive package of 13 technical farmer training packages with 53 sub-sets or lesson plans based on the needs assessments that had been carried out in the villages. In doing this work - of training, translation, preparation, teaching and writing - Karen was ably assisted throughout by Dr. Mahibullah Halimi. They were also supported, particularly in the field, by the supervisors Drs. Pushtoonzai and Shaukat.

These packages were all technically edited and evaluated by the senior programme staff including myself.

I believe that a valuable team has been developed that it will spearhead livestock development amongst women in Afghanistan. Our grateful thanks go out to them and particularly to Karen Iles who has worked so hard to develop this approach for the benefit of women farmers.

Terence J. Barker, Programme Manager, AFG/96/007
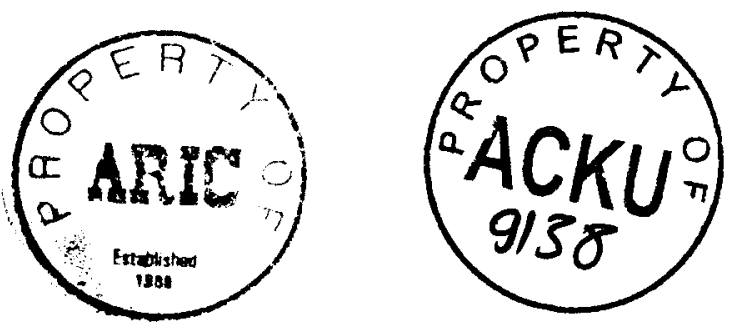


\section{Livestock Initiators Program \\ Developing Livestock Services for Women}

FARMER TRAINING PACKAGES

\section{Livestock Feeding}

1.1 Importance of balanced feed

1.2 Making a ration from local feed

1.3 Urea treatment of straw

1.4 Feeding of molasses blocks

2. Livestock Housing

2.1 How to build stable

2.2 How to improve a stable

2.3 How to build a place where animals are kept in summer

2.4 Management of stable/place to keep animals in summer

3. Livestock Diseases - treated by farmers

3.1 Examination of an animal for health/disease

3.2 Internal parasites

3.3 External parasites

3.4 Diarrhoea

3.5 Wounds/orf/sores

3.6 FMD (first aid)

3.7 Constipation

3.8 Acidosis

3.9 Tympany

4. Livestock Diseases - vaccinated
4.1 Enterotoxaemia
4.2 Blackleg
4.3 Anthrax
4.4 Sheep pox

5. Livestock diseases - zoonotic

5.1 Brucellosis

5.2 Rabies

5.3 TB

6. Management young-stock

6.1 Care of the neonate ( theory and practical )

6.2 Place for keeping young animals

6.3 Feeding suckling animals

6.4 Feeding weaned animals

7. Management of pregnant \& parturient cow/ewe 
7.1 Care before parturition

7.2 Care during parturient

7.3 Care after parturition

8. Livestock Breeding

8.1 Signs of heat

8.2 Selection of bull for breeding

9. Milking

9.1 Milking technique

9.2 Mastitis

10. Poultry feeding

10.1 Importance of balanced feed

10.2 Making a ration from local feed

10.3 Feeding layers

10.4 Feeding chicks

11. Poultry housing

11.1 How to improve an existing house

11.2 How to build a new house

11.3 Making drinkers

11.4 Making feeders

12. Poultry diseases

12.1 Coryza

12.2 Diarrhea

12.3 Fowl pox

12.4 External parasites

12.5 Internal parasites

12.6 New Castles' Disease 


\section{Livestock Initiator Program}

Developing Livestock Services for Women

\section{$\underline{\text { Farmer training packages }}$}

\section{Backyard Poultry Production}

\section{Package 10: Poultry feeding}

Livestock Production for Food Security in Afghanistan, FAO, United Nations 


\section{Package 10 Poultry feeding}

\section{Lesson 10.1 Importance of balanced feed}

Objectives By the end of the lesson the trainees will be able to explain:

- The reasons why it is important to feed chickens a balanced diet.

Method Q \& A, Group Discussion

Time $\quad 3 / 4$ hour

Materials Examples of feeds suitable for making a balanced ration - wheat, bone powder, curd, corn, alfalfa, vetch or mung beans.

Method Content

\section{INTRODUCTION}

TELL In this lesson we will learn about the importance of feeding a balanced diet to chickens.

Q \& A What problems arise if chickens are not fed a balanced diet?

\section{Key points: -}

- young chicks do not grow well and so reach maturity later

- egg production is reduced

- less eggs to eat and to sell

- chickens do not become fat so fetch a low price when sold, and there is little meat on the carcass for the family to eat

- chickens become weak and susceptible to diseases, so mortality increases

- the farmer's income is reduced

- in the end the farmer's economy is weakened. 


\section{GROUP}

DISCUSSION

Divide the trainees into groups of 4 or 5 and ask them to discuss: -

Why is it important to feed chickens a balanced diet?

\section{Key points: -}

- increase growth rate

- more meat for the family and for sale

- increase egg production

- more eggs for the family and sale

- increase resistance to disease and parasites

- reduce mortality

- increase farmer's income

- improve the nutrition of the family

- improve the economy of the family

Training aids: show the trainees examples of foods suitable for making a balanced ration for chickens eg. wheat, alfalfa hay etc

\section{$\underline{\text { SUMMARY }}$}

Summarize main key points.

\section{$\underline{\text { LINK }}$}

In the next lesson we will learn how to make a balanced ration from locally available feeds, and then learn how to feed chicks and layers 


\section{Package 10 Poultry feeding}

\section{Lesson $10.2 \quad$ Making a ration from local feed}

Objectives By the end of the lesson the trainees will be able to

- Make a good quality balanced ration for chickens, using locally available feed.

Method Practical skill lesson

Time $\quad 1 / 2$ hour

Materials 13 glasses, 13 bowls. $1 \mathrm{~kg}$ wheat, $0.5 \mathrm{~kg}$ bone powder, $05 \mathrm{~kg}$ curd, $4 \mathrm{~kg}$ corn.

$0.5 \mathrm{~kg}$ alfalfa, $1 \mathrm{~kg}$ vetch or mung beans.

PRACTICAL

SKILL LESSON

\section{INTRODUCTION.}

Tell By the end of the lesson you will be able to make a good quality balanced ration for chickens, using locally available feed.

a This is a ration that can be fed to local chickens that are outside grazing.

a This ration can be fed to all chickens over 1 week of age.

Question Have any of you prepared rations for chickens before? What is your experience?

Question Why is it important to make a balanced ration for chickens?

Key points:

- Increase egg production

- Increase of immunity against diseases

- Increase of grow rate

- Chickens start producing eggs sooner it they grow faster

- Increase feed intake of chickens

- Increase food production and income of the farmer

- Improve the economy of the farmer. 
Question What is the problem of feeding only bread to chickens?

Key points:

- Bread does not give the chickens all the nutrients it needs

- Chickens do not grow well and do not become fat

- Decrease of egg production

- Decrease of chicken's ability to resist disease

- Farmer does not get full potential from her chickens

Tell

In this lesson we will learn how to make a ration to supplement the feed the chickens are getting when they scavenge.

\section{DEMONSTRATION and PRACTICE.}

Show Show the trainees the different feeds that will be used to make the balanced ration.

Silent demonstration Trainer demonstrates making ration

Tell We will now learn to make the ration together, step by step

\section{Step 1. Preparing the area}

Tell It is important that feed is mixed in a proper place.

Question How should the area be?

\section{Key points:-}

- clean, so that the feed is not contaminated with mud as this could make the chickens sick

- dry

- free from foreign bodies (glass, nails etc) that could get into the feed and harm the chickens

Practice Ask trainees to check the area for work. 


\section{Step 2. Deciding on what proportion of each feed to give}

Question What types of teed should be included in a balanced ration'?

\section{Key points: -}

- Wheat

- Corn

- Bone powder

- Alfalfa hay

- Vetch or mung beans

- Curd

- Continuous supply of water

- Allow chickens to graze and scavenge

\section{Tell}

口 Do not keep local chickens in the house all the time

- Local chickens must be allowed to scavenge outside - this allows them to find their own food. and helps maintain a balanced diet.

Question Why is it important to measure out the feeds correctly?

\section{Key points: -}

- to make sure the ration is balanced according to the needs of the chickens

- to prevent wastage of feed

Tell We will make a ration in the following proportions: -

a corn

13 Russian glasses

a wheat:

3 glasses

bone powder

I glass

c curd powder:

2 glasses

a alfalfa hay

2 hand fulls

口 vetch/mung bean: 3 glasses

Tell This amount of feed is enough for 10 chickens for 3 weeks -- but only for chickens that are scavenging outside. 


\section{Step 3. Measuring out $\&$ mixing the ration}

Question - How can the feeds be measured out?

\section{Key points: -}

- grass can be measured out by hand, using eye and with practice

- other feeds can be measured out using glasses

Demonstrate Trainer demonstrates how to measure out and mix feeds

Practice Trainees practice measuring out and mixing feeds.

\section{Step 4. How to feed chickens this ration.}

Question When should chickens be given this ration?

Key points: -

- In the eve 


\section{SUMMARY}

- Why is it important to feed a balanced ratio to chickens"

-What are the ingredients for a balance ration for chickens?

- How much feed should be mixed for 10 chickens for one day?

- How else can chickens get feed? (grazing \& scavenging)

- What other ingredient is vital to ensure good feeding'? (water)

\section{LINK}

In the next lesson we will learn bout how to feed layers. and then how to feed chicks 


\section{Package $10 \quad$ Poultry feeding}

\section{Lesson 10.3 Feeding layers}

Objectives By the end of the lesson the trainees will be able to explain:

- How to feed laying hens correctly for improved egg production

$\begin{array}{ll}\text { Method } & \text { Q \& A } \\ \text { Time } & 1 / 2 \text { hour }\end{array}$

Materials Training aids: Balanced ration (made in the previous lesson), glasses.

Method Content

\section{INTRODUCTION}

TELL In this lesson we will learn how to feed laying hens correctly.

Q \& A How have you fed laying hens in the past? What is your experience?

Q \& A Why is it important to feed laying hens correctly?

Key points: -

- Increase egg production

- Keep hens strong and healthy

- Improve the economy of the farmer

Q \& A What are the important parts of a balanced diet for layers?

\section{Key points: -}

- GRAZING. Allow layers to graze and scavenge for themselves - they get a lot of important nutrients this way

- MIXED RATION. Supplement grazing with a mixed ration (we learnt how to make a mixed ration in the last lesson). Kitchen scraps can also be given

- WATER. Give fresh clean water throughout the day. The hen needs plenty of water to keep laying eggs. If the hen is deprived of water she will stop laying, and the farmers economy will be reduced. 
Q \& A How much mixed ration (that we made in the previous lesson) should be given per day for 10 hens who are outside scavenging during the day?

\section{Key point: -}

- One glass

Q \& A When should the layers be given the mixed ration?

Key point: -

- In the evening when they have finished grazing

Q \& A Why should laying hens be given the mixed ration separately from the other chickens?

\section{Key points: -}

- to make sure they get enough food

- if hens do not get enough food egg production can be reduced

- avoid competition for food from other chickens especially cockerels

Q \& A How should layers be given food and water?

\section{Key points: -}

- give the mixed ration in a proper feeder (we will learn how to make a feeder in another lesson)

- always give clean dry food

- give fresh clean water in a proper drinker (we will learn how to make a drinker in another lesson)

- always give clean fresh water every day.

\section{$\underline{\text { SUMMARY }}$}

\section{$\underline{\text { LINK }}$}

In the next lesson we will learn how to feed chicks. After that we will learn how to make chicken houses, feeders and drinkers. 


\section{Package $10 \quad$ Poultry feeding}

\section{Lesson 10.4 Feeding chicks}

Objectives By the end of the lesson the trainees will be able to:

- Make good quality feed for chicks, using locally available feed, and feed chicks correctly.

Method Practical skill lesson

Time $\quad 1 / 2$ hour

Materials Balanced ration (made in the previous lesson), newspaper, trays, clean cloths, maize flour, clean fresh water, sugar, spoons, chicks.

\section{PRACTICAL}

\section{SKILL}

LESSON

\section{INTRODUCTION.}

Tell By the end of the lesson the trainees will be able to make good quality feed for chicks, using locally available feed, and feed chicks correctly.

Question What is your experience of feeding chicks?

Question Why is it important to feed chick correctly?

Key points: -

- Better growth rate of chicks

- Chickens start producing (laying eggs) sooner

- Makes chicks strong and healthy so they do not become sick

- Increase the economy of the farmer. 


\section{DEMONSTRATION.}

Tell We will learn how to feed chicks step by step

Step I Preparimg of area for work

Question 1 How should the area for work be?

Key points:-

- Clean and diy

- No rubbish which could contaminate the feed and make chicks sick

Demonstrate Trainer prepares work area.

Practice Each trainee prepares her work area.

\section{Step 2 Giving water to chicks in their first day of life}

Question What should be given to chicks as soon as they hatch?

Key point:

- just water

Question Why is feed not given?

Key point: -

- the chick uses part of the egg which is in their stomach.

Tell 5 hours after hatching we can give chicks "sweet water"

Question Why do we give sweet water?

Key points: -

- For better digestion within the chicks stomach

- Help reduce constipation. 
Question How can we prepare sweet water'?

Key points:-

- l spoon sugar +1 glass water

- the water must be clean and fresh otherwise the chicks will become sick

Tell One glass of sweet water is enough for 10 chicks on the first day of life.

Demonstrate Trainer demonstrates how to make sweet water.

Practice Each trainee makes a glass of sweet water

\section{Step 3. Feeding chicks their first solid food (day 1 - 6 of life)}

\section{Tell}

- The first solid feed we should give to chicks is maize flour (not mixed feed).

- Give maize flour when the chick is almost one day old, after sweet water has been drunk.

Question Why do we give only maize flour at first?

\section{Key points:-}

- Maize flour is easy for digestion

- It is cheap (for 15 chicks we need $0.5 \mathrm{Kg}$ )

Question How is maize flour fed to the chicks?

\section{Key points: -}

- Mix flour with a little water to form granules

- Granules are easy for the chicks to eat

Tell

- Start feeding the flour granules at the end of the first day of life

- After 24 hours we can mix the flour granules with other feeds (we learnt how to make a balanced ration for chickens in the previous lesson)

- Gradually add more mixed feed to the flour granules each day - do not make sudden changes in the ration for the chicks

Note

口 On $6^{\text {th }}$ day we can feed the chicks completely on mixed feed

a Chicks should be fed in clean hygienic feeders so that they do not become sick by eating contaminated food

- We will learn how to make proper feeders in another lesson. 
Question Why is it important to make gradual changes to the chicks ration, and not suddenly change the ration?

Key point: -

- To prevent the chicks from becoming sick from digestive upsets.

Demonstrate Trainer demonstrates how to make flour granules.

Practice Each trainees practices preparing maize flour in granules for feeding to chicks.

Step 4 Material and equipment for feeding of chicks (1 - 6 days old).

Question During the first days of life which things should be used to feed chicks instead of a feeder?

Key points: -

- News paper

- Tray

- Piece of cloth

Question Why do we use these things?

Key point: -

- Easy for chicks to eat from

Tell These items must all be clean, dry and free from dirt so that the chicks do not become sick.

Demonstrate Trainer demonstrates how to prepare feed for chicks on newspaper/tray/cloth.

Practice Trainees practice 


\section{Step 5 Feeding chicks from $1-8$ weeks of age}

Tell The amount of mixed feed to give to chicks according to their age is as follows. These amounts are for TEN (10) chicks for ONE week

- Week 1 3-4 glasses

व Week 2 6-8 glasses

a Week 3 9- 10 glasses

- Week 412 glasses

口 Week $5 \quad 15$ glasses

口 Week $6 \quad 18$ glasses

口 Week 722 glasses

口 Week 825 glasses

Note

- This feed is meant to supplement the food the chicks gather themselves when grazing and scavenging

- Do not keep the chicks in the house all the time

口 Give chickens fresh clean water through out the day.

\section{PRACTICE.}

Trainees practice preparing different types of feed for chicks, and ways in which this feed can be given to chicks.

\section{SUMMARY.}

What should be given to chicks as soon as they hatch?

What should be given to chicks 5 hours after hatching?

$>$ When can chicks be given solid feed?

What type of solid feed is given to the chicks first?

$>$ What type of feed is given later?

By what age should chicks be eating standard mixed ration?

$>$ How should chicks be fed from 1 - days of age? 


\section{Livestock Initiator Program}

Developing Livestock Services for Women

\section{$\underline{\text { Farmer training packages }}$}

\section{Backyard Poultry Production}

\section{Package 11: Poultry housing}

Livestock Production for Food Security in Afghanistan, FAO, United Nations 


\section{Package 11 Poultry housing}

\section{Lesson 11.1 How to improve an existing house}

Objectives By the end of the lesson the trainees will be able to:

- Improve an existing chicken house, making it suitable for housing chickens, design based on correct specifications/characteristics, using local materials.

Methods Practical skill lesson

Time $\quad 1$ day

Materials Stones, mud, poles, straw, spades, water, buckets, a place where there is a chicken house to repair (should be at one of the trainees' homes), cups and small plate, small plastic bottles to make drinkers and feeders

\section{Method Content}

\section{PRACTICAL}

\section{SKILL LESSON}

\section{INTRODUCTION}

Tell By the end of the lesson you will be able to improve an existing chicken house, making it suitable for housing poultry, the design based on correct specifications/ characteristics, using local materials.

Question Have any of you tried to improve a chicken house before? What is your experience? What materials did you use?

Question Why is it important to know how to improve a chicken house and make it according to correct specifications?

\section{Key points:}

- disease control to keep chickens healthy

- prevent chickens from getting sick

- keeps chickens clean and free from injury

- prevent losses to the farmer due to chickens getting sick and dying

- help farmer to maintain a strong economy by keeping healthy chickens 


\section{DEMONSTRATION \& PRACTICE}

Tell We will improve this chicken house together, step by step.

\section{Step 1. Size of chicken house}

Question What size should the chicken house be for the number of chickens this farmer has?

Key points: -

- The house should be 1 meter $\times 1$ meter for 5 adult chickens

- Note: the size depends on the number of chickens the farmers has.

- If the chicken house is too small for the number of chickens. advise the farmer to keep less chickens there, and build another house.

\section{Step 2. Repairing the floor}

Question What problems arise from an uneven, poorly drained floor?

Key points:

- chickens may get dirty and uncomfortable

- atmosphere becomes moist from feces and water

- chickens may get sick from the damp atmosphere

- chickens may get sick from germs picked up from the dirty floor especially young birds

Question What are the characteristics of a good floor?

Key points:

- smooth level surface (no holes or bumps)

- dry

- no rubbish, rock or sharp objects

Look at the chicken house that has to be repaired and ask: -

Question What is your opinion of this floor? How can it be repaired?

Demonstrate Trainer demonstrates how to repair the floor.

Practice Trainees finish repairing the floor. 


\section{Step 3. Repairing the walls}

Question What are the characteristics of a good wall?

Key points:

- smooth, no sharp objects, solid, strong, no holes

- windows for ventilation

- door for access and ventilation

- perches for the chickens to sit on so they are not on the floor

Question Why is it important to have good ventilation?

\section{Key points:}

- keep the air in the house fresh and dry

- circulation of air

- damp stale air causes respiratory diseases

Question What problems arise if the walls have holes in them?

Key points:

- wind and rain comes in, chickens may get cold and sick

- dust and dirt gets in

- lice, mites and parasites can live in the cracks and holes

Question What problems arise if there are no windows in a chicken house?

Key points:

- no light and fresh air can get into the house

- the house will be dark and moist, which are conditions for disease

- there is poor ventilation

- chickens can get sick, especially from respiratory diseases

\section{Look at the chicken house that has to be repaired and ask}

Question What is your opinion of the walls of this chicken house?

How can we improve ventilation and light?

Question Where should the window be located?

Key points:

- facing the west or east sun so plenty of light gets in

- facing away from the prevailing wind, so that dust does not blow into the house and cause respiratory disease

- in the upper half of the walls for good ventilation 
Question What size should the windows be?

Key points:

- smaller than the size of a chicken (so it can't get out)

- the window should be at least $1 / 2$ meter off the ground

Demonstrate Trainer demonstrates how to repair the walls, make windows, make a door, and add perches.

- Use stones, mud and straw to fill in big holes

- Smear the walls with mud so that they are smooth

Practice Trainees finish repairing the walls, making windows, making a door, and adding perches.

\section{Step 5. Repairing the roof}

Question What problems arise if the roof leaks and is too low?

\section{Key points:}

- chickens get wet and may get sick

- poor circulation of air within the house causing spread of disease

- chickens may injure themselves

Question What are the characteristics of a good roof?

\section{Key points:}

- water proof

- no holes

- strong

- $1-1 \frac{1}{2}$ meters in height

- sloping so that water runs off

Look at the chicken house that has to be repaired and ask: -

Question What is your opinion of this roof? How can it be repaired?

Demonstrate Trainer demonstrates how to repair the roof. Trainer starts the process

Practice Trainees finish repairing the roof. 


\section{Step 6. Hygiene and management of the chicken house.}

Question Why is it important to maintain high levels of hygiene in the chicken Key points: house?

- Keep chickens healthy

- Prevent respiratory and diarrhea diseases

- Healthy chickens grow better and produce more eggs

- Healthy chickens increases the economy of the farmer

Question How should we keep the house clean?

Key points: -

- Put dry sand, soil or straw on the floor to keep it dry

- Sweep out the chicken house once a week to keep the floor clean and dry

- Clean the feeders and drinkers once week so that they do not become dirty and so contaminate the food and water

- Repair the roof and walls to prevent external parasites, and to stop rain getting inside and making the atmosphere moist

Demonstrate Trainer demonstrates how to clean the chicken house.

Practice Trainees finish cleaning the chicken houes.

\section{$\underline{\text { SUMMARY }}$}

What problems arise if the chicken house is not well ventilated?

How do we ensure good ventilation?

¿ What problems arise if we have too many chickens in a house?

W What size should a house be for 10 chickens?

Why is hygiene important in chicken houses?

How often should the house be cleaned? 


\section{Package $11 \quad$ Poultry housing}

\section{Lesson 11.2 How to build a new chicken house}

Objectives By the end of the lesson the trainees will be able to:

- Build a chicken house, making it suitable for housing chickens, design based on correct specifications/characteristics, using local materials.

Methods Practical skill lesson

Time $\quad 1$ day

Materials Stones, mud, poles, straw, spades, water, buckets, a place where a chicken house can be built (should be at one of the trainees' homes).

Method

Content

PRACTICAL

SKILL LESSON

\section{INTRODUCTION}

Tell By the end of the lesson you will be able to build a chicken house, making it suitable for housing poultry, the design based on correct specifications/ characteristics, using local materials.

Question Have any of you tried to build a chicken house before? What is your experience? What materials did you use?

Question Why is it important to know how to build a chicken house and make it according to correct specifications?

Key points:

- disease control to keep chickens healthy

- prevent chickens from getting sick

- keeps chickens clean and free from injury

- prevent losses to the farmer due to chickens getting sick and dying

- help farmer to maintain a strong economy by keeping healthy chickens 


\section{DEMONSTRATION \& PRACTICE}

Tell We will build a chicken house together, step by step.

\section{Step 1. Size of chicken house}

Question What size should the chicken house be for the number of chickens this farmer has?

\section{Key points: -}

- The house should be 1 meter square for 5 adult chickens

- Note: the size depends on the number of chickens the farmers has

\section{Step 2. Making the floor}

Question What problems arise from an uneven, poorly drained floor?

Key points:

- chickens may get dirty and uncomfortable

- atmosphere becomes moist from feces and water

- chickens may get sick from the damp atmosphere

- chickens may get sick from germs picked up from the dirty floor especially young birds

Question What are the characteristics of a good floor?

\section{Key points:}

- smooth level surface (no holes or bumps)

- dry

- no rubbish, rock or sharp objects

Demonstrate Trainer demonstrates how to make the floor. Trainer starts process.

Practice Trainees finish making the floor.

\section{Step 3. Building the walls}

Question What are the characteristics of a good wall?

Key points:

- smooth, no sharp objects, solid, strong, no holes

- windows for ventilation

- door for access and ventilation

- perches for the chickens to sit on so they are not on the floor 
Question Why is it important to have good ventilation?

Key points:

- keep the air in the house fresh and dry

- circulation of air

- damp stale air causes respiratory diseases

Question What problems arise if the walls have holes in them?

Key points:

- wind and rain comes in, the chickens may get cold and sick

- dust and dirt gets in. which can make chickens sick

- lice, mites and parasites can live in the cracks and holes

Question What problems arise if there are no windows in a chicken house?

Key poin ts:

- no light and fresh air can get into the house

- the house will be dark and moist, which are conditions for disease

- there is poor ventilation

- chickens can get sick, especially from respiratory diseases

Question Where should the window be located?

Key points:

- facing the southern sun so plenty of light gets in

- facing away from the prevailing wind, so that dust does not blow into the house and cause respiratory disease

- in the upper half of the walls for good ventilation

Question What size should the windows be?

Key points:

- smaller than the size of a chicken (so it can't get out)

- the window should be $1-11 / 2$ meters off the ground

Demonstrate Trainer demonstrates how to build the walls, make windows, make a door, and add perches

Practice Trainees finish making the walls, making windows, making a door, and adding perches 


\section{Step 5. Making the roof}

Question What problems arise if the roof leaks and is too low?

Key points:

- chickens get wet and may get sick

- poor circulation of air within the house causing spread of disease

- chickens may injure themselves

Question What are the characteristics of a good roof?

Key points:

- water proof

- no holes

- strong

- $1-1 \frac{1}{2}$ meters in height

- sloping so that water runs off

Demonstrate Trainer demonstrates how to build the roof. Trainer starts process

Practice Trainees finish making the roof.

\section{Step 6. Hygiene and management of the chicken house}

Question Why is it important to maintain high levels of hygiene in the chicken house?

Key points: -

- Keep chickens healthy

- Prevent respiratory and diarrhea diseases

- Healthy chickens grow better and produce more eggs

- Healthy chickens increases the economy of the farmer 
Question How should we keep the house clean?

Key points: -

- Put dry sand, soil or straw on the floor to keep it dry

- Sweep out the chicken house once a week to keep the floor clean and dry

- Clean the feeders and drinkers once week so that they do not become dirty and so contaminate the food and water

- If feeders and drinkers are not cleaned regularly they become dirty and can make chickens sick

- Repair the roof and walls to prevent external parasites, and to stop rain getting inside and making the atmosphere moist

Question How often should chickens be given water?

Key points: -

- Give clean fresh water every day

- Throw away any water from the previous day and add fresh water - do not just add fresh water to old water in the drinker.

\section{$\underline{\text { SUMMARY }}$}

What problems arise if the chicken house is not well ventilated?

¿ How do we ensure good ventilation?

W What problems arise if we have too many chickens in a house?

\$ What size should a house be for 10 chickens?

$>$ Why is hygiene important in chicken houses?

L How often should the house be cleaned?

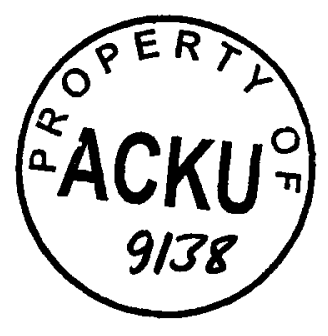




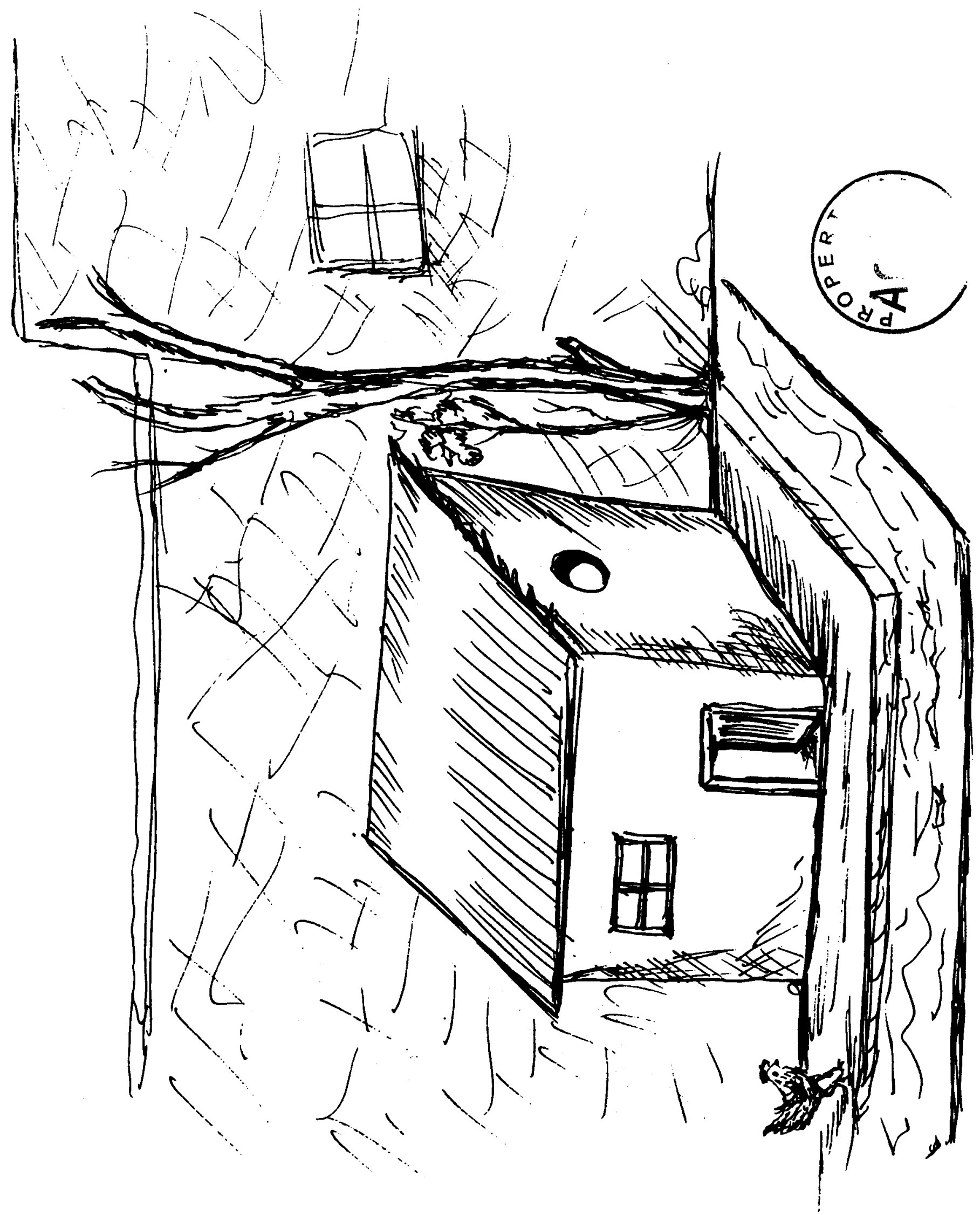




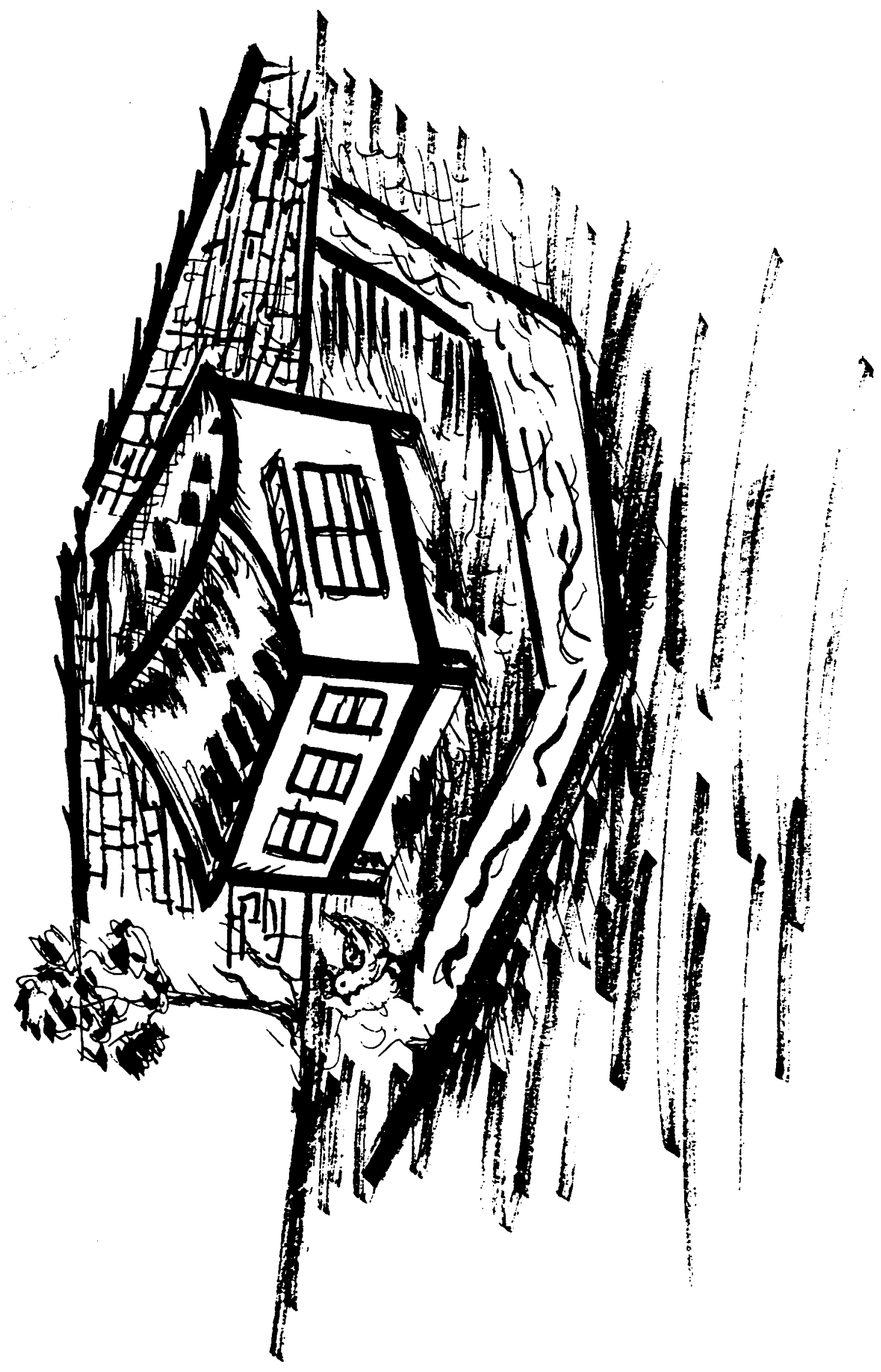




\section{Package $11 \quad$ Poultry housing}

Lesson 11.3 Making drinkers

Objectives By the end of the lesson the trainees will be able to:

- Make a drinker, design based on correct specifications, using local

Methods Practical skill lesson

Time $\quad 1 / 2$ hour

Materials Plastic beakers (cups), plastic plates, nails, water.

Method

Content

PRACTICAL

SKILL LESSON

\section{INTRODUCTION}

Tell By the end of the lesson you will be able to: -

- Make a drinker, design based on correct specifications, using local materials,

Question Have you ever made a drinker?

What is your experience?

Question Why is it important to make a good drinker?

Key points: -

- To provide clean and hygienic water to chickens

- Prevent chickens getting sick

- Avoiding contamination of water

\section{DEMONSTRATION.}

Trainer shows the trainees the materials that will be used to make the drinker.

Tell Trainer explains that she will demonstrate how to make a drinker from beginning to end. Please watch carefully. 


\section{Silent demonstration}

Trainer makes the drinker

Tell Now we will make a drinker step by step together. 


\section{Step 1. Preparing place}

Tell The first thing for making drinker is the preparation of materials for making a drinker in the area of working.

Question How should the working area be?

Key points: -

- Area should be clean, so as not to damage and dirty the drinker

- The materials should be nearby.

Demonstrate Trainer demonstrates how to prepare working area.

Practice Trainees prepare their working area.

\section{Step 2. Marking the beaker}

Question Why we are making holes in the beaker?

Key point: -

- So that water will drip onto plate

Question Why do we make two marks on the beaker for making the hole?

Key point: -

- To ensure the hole is made in the correct place.

Demonstrate Trainer demonstrate marking of beaker for making the hole

Practice Each trainee marks her beaker.

\section{Step 3. Making the hole in the beaker}

Question What size should the hole be?

Key point: -

- The size of the head of small nail, $1 \mathrm{~cm}$ (one thumb with) from the edge of the glass

Question What will happen if you make the hole smaller?

Key point: -

- The water will not drop from the glass and the chickens will get thirsty 
Question What will happen if you make the hole bigger?

Key point: -

- Too much water will drop from the hole

- Water will pour onto the floor, which will get wet and muddy and the chickens will get sick

Demonstrate Trainer demonstrates making a hole in the beaker, using the marks made previously.

Practice Each trainees makes a hole in her beaker.

\section{Step 4. Assembling the drinker}

Question How do we assemble the drinker?

Key points: -

- Pour water into the glass

- Put the plate on the glass (top of the plate facing the top of the beaker)

- Turn the glass with plate over, so the glass is upside down on the plate.

Question Why do we turn the beaker upside down on the plate?

Key point: -

- The water which is coming from the hole, accumulates on the plate for drinking

Demonstrate Trainer demonstrate how assemble the drinker.

Practice Each trainee assembles her drinker.

\section{PRACTICE.}

Trainees practice all the steps for making a drinker for chickens, and the trainer corrects the mistakes and errors.

\section{SUMMARY.}

Why is it important to make good drinkers?

-What materials can be used for making a dririker?

Why is it important to make the hole the correct size?

¿How can we assemble the drinker?

\section{$\underline{\text { LINK }}$}

In the next lesson we will learn how to make a feeder. 


\section{Package $11 \quad$ Poultry housing}

\section{Lesson 11.4 Making feeders}

Objectives By the end of the lesson the trainees will be able to:

- Make a feeder for chickens, design based on correct specifications, using local materials.

Methods Practical skill lesson

Time $\quad 1 / 2$ hour

Materials Old plastic pots, old gallon ( 5 liter) jerry cans, knives, thin rope, nails

Method Content

PRACTICAL

SKILL

LESSON

\section{INTRODUCTION}

Tell By the end of the lesson the trainees will be able to make a feeder for chickens, the design based on correct specifications, using locally available materials.

Question Have you ever made a feeder?

What is your experience?

Question Why is it important to make a good feeder?

Key points: -

- To provide clean and hygienic feed to chickens

- Prevent chickens getting sick

- Avoiding contamination of feed

- Prevent wastage of feed 


\section{DEMONSTRATION.}

Show Trainer shows the trainees the materials that will be used to make the feeder.

Tell Trainer explains that she will demonstrate how to make a feeder from beginning to end. Please watch carefully.

Silent demonstration Trainer makes the feeder

$\underline{\text { Lesson } 11+\text { practical }}$

Tell Now we will make a feeder step by step together

\section{Step 1. Preparing place}

Tell The first thing for making a feeder is the preparation of materials for making a feeder in the area of working.

Question How should the working area be?

\section{Key points: -}

- Area should be clean, so as not to damage and dirty the feeder

- The materials should be nearby

Demonstrate Trainer demonstrates how to prepare working area.

Practice Trainees prepare their working area.

\section{Step 2. Marking the gallon jerry can or plastic pot}

\section{Tell}

a We need to mark 4 places on the jerry can or pot

a The marks are $10 \mathrm{~cm}$ from the bottom of the can or pot

a Mark a square approximately $5 \times 7 \mathrm{~cm}$ in each side of the can $/$ pot, $10 \mathrm{~cm}$ from the bottom

- These square marks are where we will cut the jerry can/pot, to make holes so the chickens can out their heads through to eat the feed

- Leave the corners of the can/pot in place so that the tup of the feeder does not fall off

- These are measurements for adult chickens. For chicks make the same design but with square holes lower down eg. 3 to $5 \mathrm{~cm}$. 
Question Why we are marking the jerry can/pot?

Key points: -

- For regular straight cutting

- To make sure the feeder is the correct height for the size of chickens

Demonstrate Trainer demonstrates marking of jerry can/pot.

Practice Each trainee marks her jerry can/pot.

\section{Step 3. Cutting the ierry can/pot}

Question What will happen if you make the square holes too small?

Key point: -

- The chickens will not be able to eat properly

Question What will happen if you make the square holes too high?

\section{Key points: -}

- The chickens will not be able to reach the feed

- Small chicks will not be able to reach feed and will not grow well

Demonstrate Trainer demonstrates cutting square holes in the jerry can/pot, using the marks made previously.

Practice Each trainees cuts square holes in her can/pot.

\section{Step 4. Making a laanger for the feeder}

Tell Now we will make a hanger for the feeder.

Question Why do we need to make a hanger for the feeder?

\section{Key points: -}

- To attach a rope so the feeder can be hung and kept off the ground

- If the feeder is off the ground there is less chance of dirt getting into the feeder and contaminating the feed and making the chickens sick

- Avoid water getting into the feed and making it wet

- Prevent feed wastage.

Demonstrate Trainer demonstrates how to make the hanger.

Practice Each trainee makes a hanger for her feeder. 


\section{Step 5. Hanging the feeder}

\section{Lesson $11+$ practicill}

Question Where should the feeder be hung?

Key points: -

- In a place where it will not be disturbed by other animals

- From the roof of the chicken house

- Or, from a low branch of a tree outside, for backyard local chickens

Question What height should the feeder be hung?

\section{Key points: -}

- At a height so that the chickens can comfortably feed

- A few centimeters off the ground according to the age and size of the chickens.

\section{PRACTICE.}

Trainees practice all the steps for making a feeder for chickens, and the trainer corrects the mistakes and errors.

\section{SUMMARY.}

-Why is it important to make good feeders?

- What materials can be used for making a feeder?

> Why is it important to make the holes the correct size?

i What are the correct hole sizes for a feeder?

L How high from the bottom of the feeder should the holes be for chicks? 
Livestock Initiator Program

Developing Livestock Services for Women

\section{$\underline{\text { Farmer training packages }}$}

\section{Backyard Poultry Production}

\section{Package 12: Poultry diseases}

Livestock Production for Food Security in Afghanistan, FAO, United Nations 


\section{Package 12 Poultry diseases}

\section{Lesson 12.1 Coryza ( Influenza ) or rezish}

Objective By the end of the lesson the trainees will be able to:

- explain the causes, symptoms, spread, treatment and prevention of coryza (Influenza or rezish) in chickens.

Method Problem picture

Time $\quad 40$ minutes

Materials Picture of chicken showing respiratory problems, tribresine medicine

Method

Content

\section{INTRODUCTION}

TELL In this lesson we will learn about an important respiratory disease in chickens.

\section{PROBLEM}

PICTURE

Put up the picture for the trainees and ask them to look carefully and ask the following questions:

Question 1: What can you see in the picture?

Key points:-

- Sick chicken

- Discharge from the mouth and eyes

Question 2: What is the main problem we can see?

Key points:

- Coryza (Chicken Influenza)

- Respiratory problems

Question 3. Have you ever seen this disease before? 
Question 4. What are the main signs of Coryza?

Key points:

- Respiratory problem

- Abnormal sound during breathing

- The chicken becomes weak

- Loss of appetite

- Discharge from the eyes and nose

- Swelling of face and head

- Change in the colour of crown, which becomes red blackish

Question 5: Why is Coryza or Influenza a problem?

Key points:-

- Reduce the egg and meat production

- The chicken becomes weak

- Reduced income and food for the family

- Weak economy of the farmers

Question 6. What are the causes of Coryza?

Key points:-

- Micro organism

Question 7. What are the predisposing factors for Coryza?

Key points: -

- Lack of hygiene

- Over crowding of chickens

- Keeping of sick chickens with healthy chickens

- Sudden change in weather to cold weather

- Lack of light and sun

- Poor ventilation in the chicken house

- Wet muddy conditions in the chicken house

Question 8: How is Coryza spread from one chicken to another?

\section{Key points: -}

- Contaminated feed

- Respiratory discharge

- Direct contact 


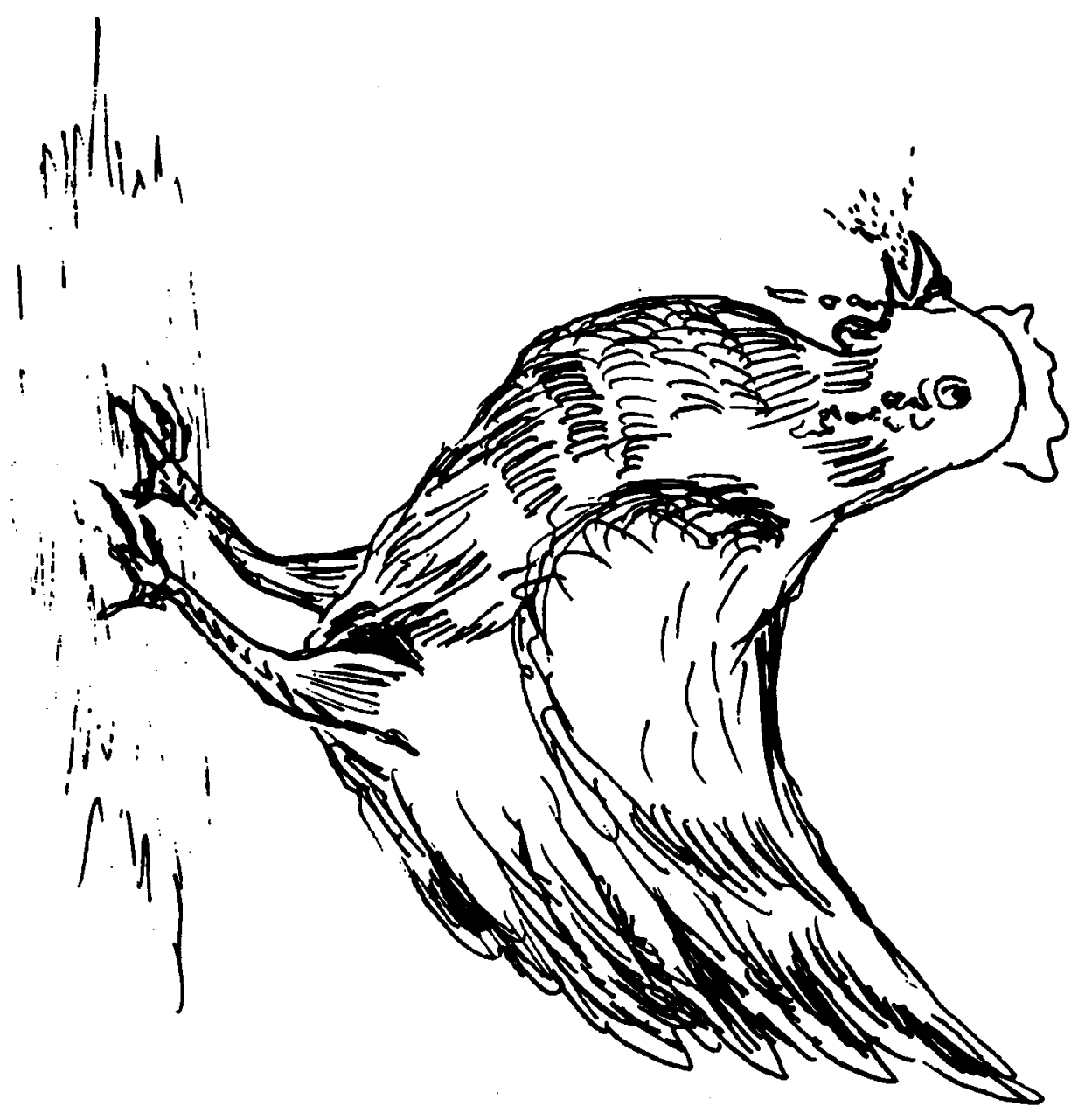


Question 9: How can Coryza be treated?

Key points:-

- Use tribresine and water (Put 4 drops of tribresine in 2 glasses of water for 15 chicken).

- Treatment should be followed for 3-5 days.

Training aid: show trainees the medicine that can be used.

Question 10: How can Coryza be prevented?

Key points:-

- Avoid over crowding in the chicken house.

- Separate diseases chicken from healthy chicken

- Treat sick chickens

- Maintain hygienic condition

\section{$\underline{\text { SUMMARY }}$}

\section{$\underline{\text { LINK }}$}

In the next lesson we will learn how to treat chickens with coryza practically. 


\section{Package 12 Poultry Diseases}

\section{Lesson 12.2 Diarrhea (Theory)}

Objectives By the end of the lesson the trainees will be able to explain: Sign, causes, spread and treatment of white diarrhea in poultry

Methods Problem Picture

Time $\quad 45$ minuts

Materials Picture of a sick hen with white diarrhea

\section{INTRODUCTION}

Tell In this lesson we will learn about the sign, causes, spreading and treament of white diarrhea in poultry

PROBLEM Picture of a sick hen with white diarrhea

PICTURE

Question 1: What can you see in this picture?

Key points:

A hen with diarrhea

Question 2: What disease do you think this is?

\section{Key points:}

Diarrhea

Question 3: Have you seen diarrhea before in your chicken? What is your experience?

Question 4: What are the signs of diarrhea?

Key points:

Weakness 
White diarrhea

Chicken are feeling thirsty

Decrease in production

The anus is covered with whitish dirt

Death of the hen

Question 5: Why diarrhea is a problem?

Key points:

Farmer will not have income from keeping such chicken

Spending money for treament

Atfected chicken spreading dirrhea very soon to other chicken

Affected chicken remain as carrier in the herd

Question 6: What is the cause of diarrhea?

Key points:

Bad hygein

Contaminated eggs

Sick chicken as carrier

Buying of affected chicken from the bazar

Microorganism

Question 7: How diarrhea is spreading from chicken to chicken?

Key points:

Affected chicken in the flock spread the diarrhea very soon Through contamination of the chicken house with feces

The person who has direct contact with the affected chicken

Question 8: What is the treatment for diarrhea in chicken?

Key points:

Put four drops of tribrisin in the water and leave the chicken to drink

Training aids: Show tribrisin solution to the trainees

Question 9: How can we prevent diarrhea?

Key points:

Clean chicken house where chicken are kept

Separate sick chicken from healthy chicken 
Treatment of affected chicken as soon as posible Avoid buying of affected chicken from outside Consider strict hygienic condition in the flock Avoid entrance of outsiders in the flock

Check eggs properly for hatching

\section{$\underline{\text { SUMMARY }}$}

What are the signs of diarrhea?

How diarrhea is spreading?

How diarrhea can be prevented?

How diarrhea can be treated?

\section{LINK}


Chicken drink continously which maintain the required dose

Question How much water will be mixed with 4 drops of tribrisin?

Key point:

2 glasses ( half liter)

Demonstration Trainer demonstrate measuring and mixing of water with tribrisn in the glass

Practice Trainees practicing measuring and mixing of water with tribrisin in the glass

Tell Trainer should tell the trainees that during mixing of water with tribrisin should be shacken well in order to make proper solution.

\section{Step 4 Drinking of tribrisin solution to chicken}

Question How the solution should be given to the chicken?

Key points:

Put the solution in a drinker infront of the chicken

Question How many days tribrisin should be given to the chicken?

Key points:

5 days

Tell While giving tribrisin solution, extra water should not be given to the chicken to drink.

Question Why extra water should not be given to the chicken?

Key points:

The chicken will not drink tribrisin solution

Demonstaration Trainer demonstrate puting of tribrisin solution infront of chicken in a drinker

Practice Trainees practicing puting of tribrisin solution 
infront of chicken in a drinker

\section{Practice:}

Trainees are practicing all the steps of tribrisin solution and the trainer correcting the mistakes

\section{Summary:}

Why treatment of diarrhea is important?

What medicine are you using for the treatment of diarrhea?

How much tribrisin should be mixed with how much water?

How many days tribrisin should be given to the chicken affected with white diarrhea?

Link to the next lesson 
Pakage 12 Poultry Diseases *

Lesson 12.3 Fowl Pox

Objectives By the end of the lesson the trainees will be able to explain Sign, causes, spread. treatment and prevention of Fowl Pox

Methods Problem Picture

Time $\quad 45$ minutes

Materials Picture of a chicken affected with Fowl Pox

\section{INTRODUCTION}

Tell In this lesson we will learn about the sign, causes, spreading, prevention and treatment of external parasites in chicken

PROBLEM Picture of a chicken affected with Fowl Pox

PICTURE

Question 1: What can you see in this picture?

Key points:

A chicken

Black spots on the crown and face

Question 2: What disease do you think this is?

Key points:

Fowl Pox

Question 3: Have you seen Fowl Pox before in your chicken? What is your experience?

Question 4: What are the signs of Fowl Pox in chicken? 


\section{Key points:}

Black and yellow spots on the head, crown and face Lack of appetite

Low production

The chicken is dull and not interested with his srounding

Question 5: Why Fowl Pox is a problem?

Key points:

Economic loss for the farmers due to the death and low production of the chicken.

Spread the diseases to other chicken

Question 6: What are the causes of Fowl Pox?

Key points:

Microorganism

Question 7: What are the predisposing factor of Fowl Pox?

Key points:

Crowding of chicken in a chicken house

Lack of feed

Question 8: How Fowl Pox is spreading from one chicken to other chicken?

Key points:

Direct contact of the affected chicken

Contaminated feed

Mosquito and other insects

Question 8: What is the treatment for Fowl Pox?

Key points:

No treatment

The lesions should be washed with water-salt solution or potassium permanganate solution

Tell Making of potassium permanganate solution is the as for washing 
the wounds

Training aids: $\quad$ Show a potassium permanganate solution

Question 9: How can we control Fowl Pox?

Key points:

Clean chicken house where chicken are kept

Separate chicken affected with Fowl Pox

Do vaccination

Avoid contamination of feed, water

$\underline{\text { SUMMARY }}$

How Fowl Pox is spreading from one chicken to other chicken?

What are the signs of Fowl Pox?

How Fowl Pox can be prevented?

How Fowl Pox can be treated?

$\underline{\text { LINK }}$ 
Pakage 12 Poultry Diseases *

Lesson 12.4 External parasites (Theory)

Objectives By the end of the lesson the trainees will be able to explain

Sign, causes, spread and treatment of external parasites in chicken

Methods Problem Picture

Time $\quad 45$ minuts

Materials Picture of a weak clicken with external parasites (lice/ticks)

\section{INTRODUCTION}

Tell In this lesson we will learn about the sign, causes, spreading and treament of external parasites in chicken

PROBLEM Picture of a weak chicken with lice

PICTURE

Question 1: What can you see in this picture?

Key points:

A weak chicken with lice

Question 2: What disease do you think this is?

Key points:

Chicken having lice

External parasite

Question 3: Have you seen lice before in your chicken?

What is your experience?

Question 4: What are the signs of external parasites in chicken? 


\section{Key points:}

\section{Weakness}

Anemia

Lack of appetite

Low production

Feet colored with blood

Due to weakness the chicken are dying

Question 5: Why are external parasites problem?

Key points:

Economic loss for the farmers due to the death and low production of the chicken.

Spread the diseases to other chicken

Question 6: What are the causes of external parasites?

\section{Key points:}

Bad hygeinic condition

Dirty chicken house

Presence of holes in the chicken house

Moisture in the chicken house

lack of sun shine

Question 7: What are external parasites?

\section{Key points:}

Lice, ticks, fleas, etc.,

Question 8: What is the treatment for external parasites?

\section{Key points:}

Neguvon solution

Tell Teatment with neguvon solution will be discussed later on

Training aids: Show a piture of healthy chicken without external parasites

Question 9: How can we contro external parasites? 
Key points:

Clean chicken house where chicken are kept

Separat chicken with external parasites

Treatment of affected chicken as soon as posible

Provide proper ventilation and sunshine in chicken house

Spray chicken house with acaricide as soon as the external parasites appeared.

Avoid moisture in the chicken house.

\section{SUMMARY}

What are the signs of external parasites in chicken?

What are external parasites in chicken?

How external parasites in chicken can be prevented?

How external parasites in chicken can be treated?

LINK 


\section{Package 12 Livestock Diseases - treated by farmers}

Lesson 12.4 Treatment of External Parasites in poultry (practical)

Objectives By the end of the lesson the trainees will be able to:

- Prepare a solution of Neguvon and water, mixed in the correct proportions.

- Dipping the chicken with Neguvon solution correctly with out injury to the chicken or themselves.

Methods Practical skill lesson

Time $\quad 1 / 2$ hour

Materials Neguvon powder, bucket, stick, gloves (or plastic bag) and chicken

Note to trainer: The theory lesson on external parasite must be given before this lesson.

PRACTICAL

SKILL LESSON

\section{INTRODUCTION}

Tell In this lesson we will learn how to make a solution for control external parasite.

By the end of the lesson you will be able to:

a Prepare a solution of Neguvon and water, mixed in the correct proportions.

a Dip the chicken in Neguvon solution correctly with out injury to the chicken or themselves.

Question: Have any one of you prepaired solution of Neguvon?

Question: Why we are prepairing Neguvon solution?

Key points: 
To control external parasit (eg. Lice, tick)

To remove external parasites from the chicken

To make the chicken calm from harming of external parasites

To avoid transfering of diseases from one chicken to other chicken

To improve the health and production of chicken

\section{Part 1 - Making of Neguvon solution}

\section{DEMONSTRATION.}

Tell

a First we will learn how to mix Neguvon and water, in the correct proportions.

a The equipment we need is Neguvon powder, water, a bucket, a spoon, gloves or plastic bag, clean water and stick.

\section{Silent Demonstration}

The trainer demonstrates the whole process of making a mixture of Neguvon.

Tell We will now learn how to prepare a Neguvon mixture for deeping a chicken step by step.

\section{Step 1. Selecting the proper equipment}

Question How should the pots, bucket and spoons be?

Key points: -

- clean,

- of the correct size (spoon, bucket)

Demonstrate Trainer demonstrates the correct size and condition of the equipment.

Practice Trainees select and check their equipment

Step 2. Measuring out the Neguvon powder

Show the Neguvon powder to the trainees. Note the colour and the smelling of the Neguvon powder. Trainees examine colour and smelling of the powder.

Question: How much powder of Neguvon is needed to put into the bucket? 
Key point: -

- One table spoon (15 grams)

Demonstrate Trainer demonstrates how to measure out the Neguvon powder by spoon and adds it into the bucket.

Practice Each trainee measures out Neguvon powder by spoon and adds it into the bucket

\section{Step 3. Measuring out the water}

Question How much water is mixed with one table spoon of Neguvon powder?

Key point: -

. 2 gallons ( 10 liters)

Demonstrate Trainer demonstrates how to measure out 2 gallons of water, and adds it to the powder in the bucket. Shake the mixture by a stick to mix the powder with the water properly.

Practice Each trainee measures out water and adds it to the bucket.

\section{Part 2 - Dipping of chicken}

\section{Step 4 Dipping of chicken}

Tell Now we will dip the chicken with the prepared Neguvon solution.

Question : Why the deeping of chicken in Neguvon solution is important?

Key point:

Remove all external parasite (lice,ticks) from the chicken

Make the chicken calm and happy when the extenial parasites are removed Improve production

Avoid transmission of diseases 
Make the chicken healthy

Question : How can the chicken will be dipped?

Key point:

Wear the gloves or plastic bag to you hands

Hold the chicken from the its nick and dip the chicken into the solution avilable in the bucket for one time

Tell Do not hold the nick of the chicken too firmly that cause asphexation and the death of the chicken

Demonstration: Trainer demonstrate how to dip the chicken

Practice: $\quad$ Trainees practicing diping of the chicken

\section{Step 5. Cealining of equipment}

Question Why do we cleaning the equipment at the end?

Key point:

To avoid poisoning of the children and familly members during accidently use of the equipment

Demonstration: Trainer demonstrate how to clean the equipment

Practice: $\quad$ Trainees practicing cleaning of equipment

\section{PRACTICE}

Each trainee practices making solution and dipping her owu animal

\section{SUMMARY:}

- What is Neguvon solution used for? (Remove extemal parasites)

- How much Neguvon powder is mixed with water? ( One table spoon or 15 grams)

- How much water is mixed with Neguvon powder? ( 2 gallons or 10 liters) 
- How can we dip a chicken into Neguvon solution? ( hold the chicken from the nick and dip it for one time) 


\section{Package 12 Poultry disease}

\section{Lesson $12.5 \quad$ Internal parasites}

Objectives By the end of the lesson the trainees will be able to explain

- Sings, cause, transmission, of internal parasites in poultry

Method Problem picture

Time $\quad 1 \mathrm{hr}$

Material Picture of chicken with worm

Introduction We are going to learn about internal parasites in poultry

Problem picture

Picture of chicken with worm, chicken is thin and weak,

Question 1 What can you see in the picture?

Key points:

- A chicken

- The chicken is very weak

- The chicken is very thin

- Worm can be seen in the manure of chicken

Question 2 What disease do you thin this is ?

Key point:

- Worms

Question 3 Have you seen worms before in your chicken?

What is your experience?

Question 4 What are the singe of worm?

Key point :

$\begin{array}{ll}\text { - } & \text { Weakness } \\ \text { - } & \text { Liarrhea } \\ & \text { Less of production, Loss of, weight, mortality }\end{array}$

Question 5 What is the caus of worm in chicken?

Key point:

- $\quad$ Bad feeding

- Un clean feeding 
- Dirty water

- Non hygiene of chicken house

- Grazing of chicken in out site of the house which is very dirty

Question 6 How can be transmit it from one to other chickens ?

Key point :

- By contaminant feeding

- By contaminant environment

- By purchased of new chicken

- Keeping of height number

Question 7 How can be control worm in poultry ?

Key point:

- Good hygiene

- $\quad$ Provide of clean food and water

- Isolation of sick chickens

- Keeping height number of chicken in small hencoop

\section{SUMMARY}

- Why are worm a problem for poultry and farmer?

- Why is it important to prevent worms ?

- How can worm be prevented ?

LINK 


\title{
Lesson 12.5 Treatment of internal parasites in poultry
}

\author{
Objectives By the end of the lesson the trainees will be able to \\ de worm chicken against internal parasite with correct dose safely without spoiling \\ The medicine to the chicken
}

$\begin{array}{ll}\text { Method } & \text { Practical skill lesson } \\ \text { Time } & 1 \mathrm{hr} \\ \text { Material } & \text { Coo pen. Chirken ratiun, tea spoon, feeder. }\end{array}$

Note to the trainer : the theory lesson on internal parasite must be given before this lesson

INTRODUCTION

Tell In this lesson we will learn how to de worm chicken with coo pen powder for control of internal parasite and deworm the chicken against internal parasite

PRACTICAL

Skill lesson

Question: Have any one of de wormed your chicken with coo pen?

Question: Why we are de worming with Co pean ?

Key points:

- To control internal parasite

- To remove internal parasite

- To make the chicken calm from internal parasite

- To avoid chicken from getting other diseases (diarrhea)

- To improve the health and production of chicken .

\section{DEMONSTRATION}

Tell First we would like to know how to mixed coo pen powder with chicken Feed by right way

The medicine that we are used for de worming is coo pen

Silent demonstration The trainer demonstrate all process of de worming in chicken step by step

Tell We would like to learn how to de worm chicken step by step

\section{Step 1 Selection of the proper medicine}

Question How should be the medicine?

Key points:

- The medicine should not be expired

- The colour of medicine should not be changed

- The bottle should not be broken 


\section{Step 2 Measuring proper dose of coo pen powder}

Question why we should know proper dose of coo pen?

Key points:

- Low dose of coo pen will not effective

- Height dose of coo pen will causing toxication

- Wasting of medicine damaged farmer economic

Question What is the proper dose of coo pen powder for chicken?

Key points:

- For ten chicken(2-mount old) $8 \mathrm{gr}$ should be consider with $1 \mathrm{~kg}$ ration( $8 \mathrm{gr}$ equal to two tea spoon)

Question How often chicken should be de worm ?

Key points:

Twice a year

Demonstration: Trainer demonstrate and measure the coo pen pow according the number of chicken

Practice : Each trainees should practice the measure of coo pen

\section{Step 3 Mixing of coo pen powder with ration}

Question Why we are mixing coo pen powder with ration?

Key points

- Powder can not be eaten by chicken

- Pow can not be mixed with water

Demonstration: trainer will demonstrate mixing of coo pen with ration

Practice Trainees will practice mixing of coo pen with ration

\section{Step 4 Adding of a little water whit above mixture}

Question Why we add a little water with mixture

Key points:

- $\quad$ Chicken will be able to eat it

- It is easy to eat it

Demonstration :Trainer will demonstrate mixing of powder with water

Practice : Tiainees will practice mixing of powder with water 


\section{Step 5: Placing of mixture in feeder}

Question Why we place mixture in the feeder?

Key points :

- The ration will not wasted

- To keep clean ration

Demonstration : Trainer should put $1 \mathrm{Kg}$ of ration with $8 \mathrm{gr}$ Co pean for 10 chicken in the feeder.

Practice : $\quad$ Each trainee will be practice all the steps for de worming of her/his chicken by Given Co pean/ration mixture from the beginning up to the end.

\section{SUMMARY:}

- What should we do if our chicken are suspected for having worms ?

- How much Co pean powder should give to 10 chicken ?

- How often Co pean powder should give to chicken ?

- Why should we mix Co pean powder with ration and do it a little moisty ? 


\section{Package 12 Poultry diseases}

\section{Lesson 12.6 Newcastle Disease (Morgh Margee)}

Objective By the end of the lesson the trainees will be able to explain:-

- the causes, symptoms. spread, treatment and prevention of Newcastle Disease (Morgh Margee) in chickens.

Method Problem picture

Time $\quad 40$ minutes

Materials Picture of a chicken with Newcastles Disease

Method Content

\section{INTRODUCTION}

TELL In this lesson we will learn about an important respiratory disease in chickens.

Put up the picture for the trainees and ask them to look carefully and ask the following questions:

Question 1: What can you see in the picture?

Key points: -

- Sick chicken

- The head is turned to the back

- The chicken looks paralyzed

Question 2: What is the main problem we can see?

Key points:-

- Newcastle Disease ( Morgh Margee)

- Paralyzed chicken

Question 3: Have you ever seen Newcastle's Disease before? 
Question 4. What are the main signs of Newcastle Disease?

\section{Key points:-}

- Sudden death

- Nervous signs

- The head turns on to the back

- Beak towards the ground

- Wings are fallen down and paralyses

- Some time circling movement around himself

- Greenish diarrhea.

Question 5: Why Newcastle Disease is a problem?

\section{Key points:-}

- Sudden death of chickens

- Can kill many chickens in one go

- The disease is very contagious and spreads easily to other chickens

- Reduce the egg and meat production

- Reduced food and income for the family

- Weakens the economy of the farmers

Question 6: What are the causes of Newcastle Disease?

\section{Key points: -}

- Micro organism ( Virus)

Question 7. What are the predisposing factors for Newcastle's Disease?

Key points: -

- Lack of hygiene

- Over crnwding of chickens

- Keeping of sick chickens with healthy chickens

- Lack of vaccination 
Question 8. How is Newcastle's Disease spread from one chicken to another?

Key points: -

- Lack of hygiene

- Contaminated feed and air

- Keeping of diseased and healthy chicken together

- Dircct contact of sick chickens with healthy chickens

- People can spread the disease on their clothes and shoes

Question 9: How Newcastle Disease can be treated"

Key points:

- No treatment

Question 10: How Newcastle Disease can be prevented?

Key points:-

- Vaccination - you must vaccinate adults every 6 months

- Vaccination - vaccinate young chicks at: (check dates!!!!!!!!!!!)

- I week of age

$\therefore 3$ weeks of age

* 3 months of age

- Separate diseases chicken from healthy chicken

- Remove all sick chicken

- Keep hygienic condition

- People should not handle sick chickens and then go to another farmer.

otherwise they will spread the disease.

\section{$\underline{\text { SUMMARY }}$}

$\underline{\text { LINK }}$ 


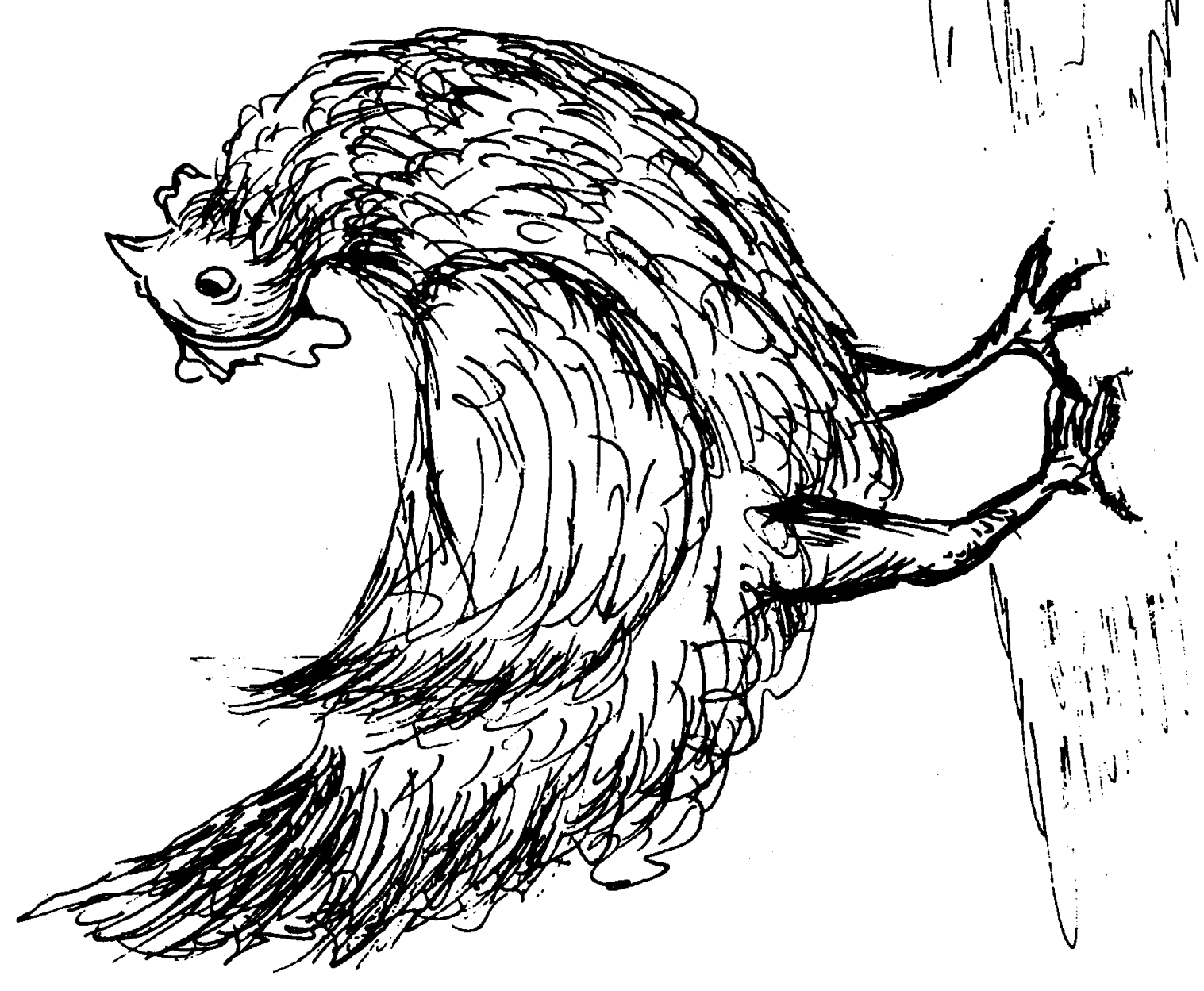




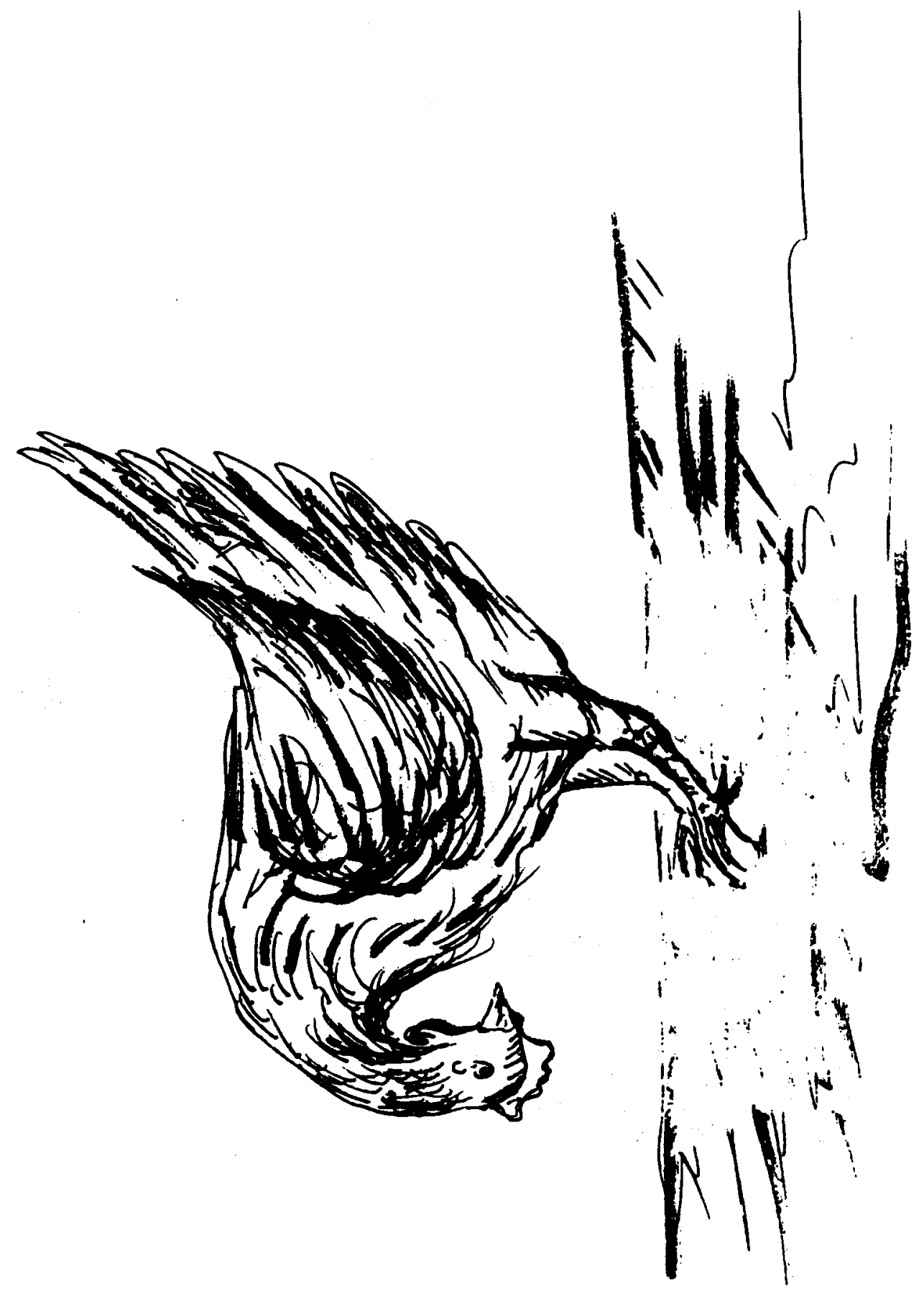




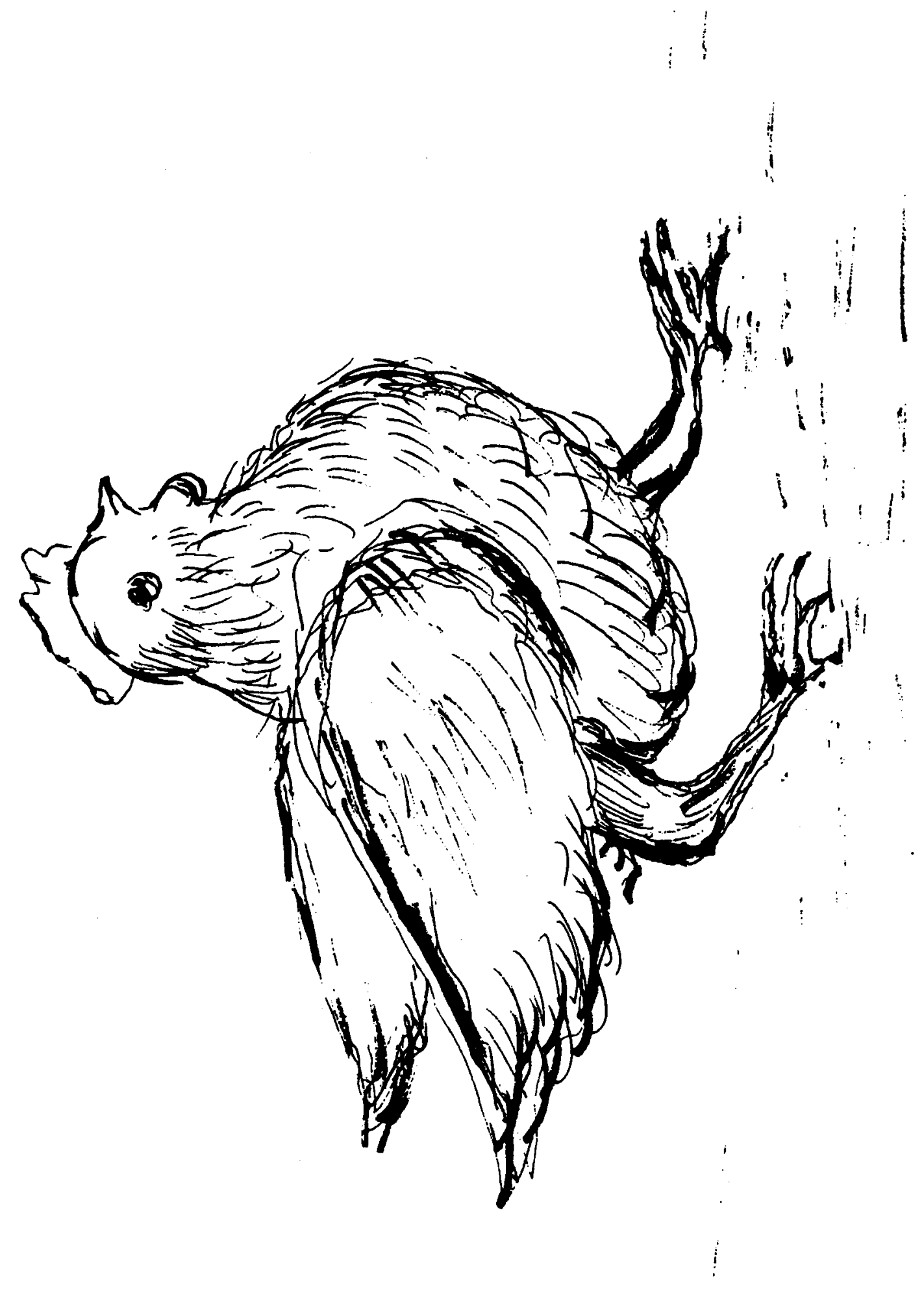


Livestock Initiator Program

Developing Livestock Services for Women

\title{
$\underline{\text { Farmer training packages }}$
}

\author{
Backyard Poultry Production
}

\section{Package 13: Poultry breeding}

Livestock Production for Food Security in Afghanistan, FAO, United Nations 


\section{Package 13 Poultry breeding}

\section{Lesson 13.1 Selection of eggs for hatching}

Objectives By the end of the lesson the trainees will be able to:

- Select suitable eggs for hatching by visual examination and candling

- Explain the characteristics of eggs suitable for hatching

Methods Practical skill lesson

Time $\quad .45$ minutes

Materials Normal eggs with embryos. abnormal eggs, eggs with no embryos, candles, matches, a dark room where all the trainees can go in order to learn how to do candling (eg. inside a trainee's house).

Method

Content

Note to trainer For this lesson you need plenty of eggs, both normal and abnormal so that the trainees get plenty of practice recognizing normal, fertile eggs.

PRACTICAL

SKILL LESSON

INTRODUCTION.

Tell By the end of the lesson you will be able to

- Select suitable eggs for hatching by visual examination and candling

- Explain the characteristics of eggs suitable for hatching

Question Have any of you examined and selected eggs for hatching before? How did you do it? What was your experience?

Question Why is it important to select good eggs for hatching?

Key points: -

- To obtain healthy chicks

- Increase hatching rate (from the number of eggs the broody hen sits on) 


\section{DEMONSTRATION.}

Show Trainer shows the materials that will be used in the lesson.

Tell We will learn how to select good eggs for hatching step by step.

\section{Step 1. Age of eggs}

Question What problems arise if we select old eggs for hatching?

Key points: -

- They are unlikely to be fertile and so it is a waste of time putting them under the broody hen

- Eggs go rotten

- Reduced number of chicks that are hatched per broody hen

- In the end the economy of the farmer is reduced

Question What age should eggs be for hatching?

Key points: -

- 1-3 days

\section{Step 2. Shape of eggs}

Question What should the shape be of healthy eggs?

Key points: -

- Oval shape

- Regular

- No bumps

- Not double yoked (lump in shell)

Demonstrate Trainer demonstrates selection of eggs with a good shape Trainer demonstrates selection of eggs with a bad shape, to illustrate the difference.

Practice Trainees select eggs with a good shape 


\section{Step 3. Egg shell characteristics}

Question What are the characteristics of a good shell for eggs suitable for hatching?

Key points: -

- Shell should be intact with no cracks

- Not broken

- Smooth, matt surface

- Shell should feel strong when held in the hand

- Shell should not be thin

- Shell should not be translucent

Demonstrate Trainer demonstrates selection of eggs with a good shell. Trainer demonstrates selection of eggs with a bad shell, to illustrate the difference.

Practice Trainees select eggs with a good shell

\section{Tell}

- Do NOT wash the eggs

- If eggs are washed the pore open and the eggs dry out and the embryo dies

- Microbes can also enter the pores if the egg is washed, and cause infection.

\section{Step 4. Candling eggs}

Question Why is it important to ensure that eggs are fertile?

Key points: -

- To maximize the potential number of chicks that could be hatched by making sure that all the eggs put under the broody hen are fertile

- Increase number of chicks hatched overall

- Increase meat production and income for the farmer

Tell We need to check that there is an embryo in each egg.

Question How can we check that eggs have an embryo?

Key points: -

- By candling - looking through an egg using a candle

- Candling allows us to see the embryo, if there is one there 
Demonstrate Trainer demonstrates and explains how to do candling. -

Key points: -

- Observe the eggs in a dark place, so that you can easily see the embryo

- Hold the egg in one hand

- Hold the candle behind the egg so that the light shine through

- If the egg has an embryo. you should be able to see it as a small dark spot about $2-4 \mathrm{~mm}$ in size

- The hole increases in size by $1.5 \mathrm{~mm}$ every day.

Trainer also shows what an egg with no embryo looks like.

Practice Each trainee practices candling eggs

\section{PRACTICE.}

Using a selection of different types of eggs, trainees practice the whole process of selecting eggs suitable for hatching, and candling eggs.

\section{SUMMARY.}

Why is it important to select good eggs with embryos in for putting under the broody hen for hatching?

What are the characteristics of a good egg suitable for hatching?

- How should the shell be of a good egg suitable for hatching?

- How do we know if an egg has an embryo in?

\section{LINK.}

In the next lesson we will learn how to manage the broody hen. 


\section{Package $13 \quad$ Poultry breeding}

\section{Lesson 13.2 Management of the broody hen}

Objectives By the end of the lesson the trainees will be able to

- Make a place for broody hens based on correct characteristics, using local materials.

- Explain how to manage a broody hen

Methods Practical skill lesson

Time $\quad 45$ minutes

Materials Baskets, grass, sand, straw, drinker, feeder, water, broody hens.

PRACTICAL

SKILL LESSON

\section{INTRODUCTION.}

Tell By the end of the lesson the trainees will be able to make a place for broody hens based on correct characteristics, using local materials; and explain how to manage a broody hen.

Question What is the importance of making a good place for broody hens?

Key points:-

- Avoid loosing eggs, from being eaten by predators

- The hen can sit calmly and undisturbed on the eggs

- Ensure enough moisture for the eggs

- Provide enough feed and water for the hen so she stays healthy

- Hatch healthy chicks

Question Have any of you made a place for broody hens? What is your experience? 


\section{DEMONSTRATION.}

Restate objective. Show trainees materials

\section{Silent demonstration}

Show the trainees the whole process of making a place for a broody hen. Ask them to watch carefully

Tell We will now learn how to make the broody place step by step

\section{Step 1. Preparing the basket}

Question What should be the length, width and height of a broody basket for one hen?

Key points: -

- $\quad$ Length $=3$ hands

- Width $=2$ hands

- $\quad$ Height $=2$ hands

Demonstrate Trainer shows how to measure the length, width and height.

Practice Each trainee cliecks the size of her basket.

\section{Step 2. Dividing the height of the basket}

Question Why do we divide the height of the basket into three parts?

Key point: -

- To make three layers of nesting material (sand, grass and straw)

Demonstrate Trainer demonstrates how to divide the basket in 3 layers

Practice Each tiainee divides her basket into 3 parts.

\section{Step 3. Making the grass layer}

Question Why do we put grass in first?

Key point: -

- Prevent cold and damp getting into the basket 
Question How much grass is out in the basket?

Key point:

- A hand full

Question Why should the grass be pressed down?

Key points: -

- To make the base of the nest strong so that it is not destroyed by the hen's feet

- To make sure the 3 layers don't mix, which could break the eggs.

Demonstrate Trainer demonstrates making the grass layer

Practice Each trainee makes the grass layer in her basket.

\section{Step 4. Making the sand layer}

Question Why do we put sand as the second layer?

Key points: -

- To help keep the eggs warm and moist

- Stabilize the moisture levels in the nest

- Safe hatching

Demonstrate Trainer demonstrates how to make the sand layer

Practice Trainees make their sand layer.

\section{Step 5. Making the straw layer}

Question Why do we put a straw layer on top of the sand layer?

Key points: -

- Safety of the eggs, the straw forms a cushion so the eggs do not get broken

- Keep a stable temperature in the nest

- Keep the eggs warm

- Safety of the embryo in the eggs

- Confort and wellbeing of the hen. 
Question What kind of straw should we use?

Key points: -

- Fresh, clean, dry straw

- Do not use wet dirty straw - this is unhygienic, will not keep the eggs at the correct temperature, will spread germs to the chicks and make them sick when they hatch.

Demonstrate Trainer demonstrates how to make the straw layer

Practice Each trainee makes a straw layer in her basket

\section{Step 6. Making a proper pliace for eggs}

Question Why should a proper place be made for the eggs in the basket?

Key points: -

- The eggs do not fall out of the basket

- All the eggs are close together

- The eggs are in a place which can fit under the breast of the hen

Demonstrate Trainer demonstrates how to make the proper place for eggs, by rearranging the straw.

Practice Each trainee makes a proper place for eggs:

\section{Step 7. Making the straw moist}

Question Why do we sprinkle a little water over the straw?

Key point: -

- To keep the environment for the eggs at the correct moisture, the environment should not be too dry

Demonstrate Trainer demonstrates sprinkling a little water over the straw

Practice Each trainee sprinkles water over the straw 


\section{Step 8. Placing the nest, water and feeder in the chicken house}

Question Where should the nest be placed?

Key points: -

- In a quiet dark corner of the house

- Away from the door, perches and places where other hens will walk

- The broody hen must be able to sit on the eggs undisturbed by other hens

- The broody hen must feel safe and secure

- Do not allow children to disturb the hen

Question Where do we place the drinker?

Key points: -

- At the side of the hen coop

- Away from the door where it can easily be knocked over by hens

- Not under perches, where feces can fall into the water

Question Where do we place the feeder?

Key points: -

- At the side of the hen coop

- Away from the door where it can easily be knocked over by hens

- Not under perches, where feces can fall into the feed

Tell

- There must be water available for the broody hen at all times

- Change the water every day, so the hen always has fresh water

- Provide supplementary feed (we learnt have to make a ration in a previous lesson).

\section{SUMMARY.}

$>$ Why is a good nest important for a broody hen?

$>$ What materials are used?

How are the layers made up?

-Where must the nest be placed in the hen coop? Why there?

$\checkmark$ How should the broody hen be managed?

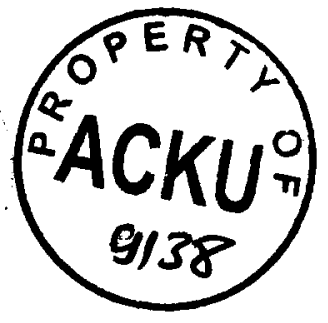

